\title{
Spatial and seasonal distribution
} of Bulinus globosus and Biomphalaria pfeifferi in Ingwavuma, uMkhanyakude district, KwaZulu-Natal, South Africa: Implications for schistosomiasis transmission at micro-geographical scale

Tawanda Manyangadze ${ }^{1,2^{*}}$, Moses John Chimbari ${ }^{1}$, Owen Rubaba', White Soko ${ }^{1,3}$ and Samson Mukaratirwa ${ }^{4,5}$

\begin{abstract}
Background: Schsistosomiasis is endemic in sub-Saharan Africa. It is transmitted by intermediate host snails such as Bulinus and Biomphalaria. An understanding of the abundance and distribution of snail vectors is important in designing control strategies. This study describes the spatial and seasonal variation of B. globosus and Bio. pfeifferi and their schistosome infection rates between May 2014 and May 2015 in Ingwavuma, uMkhanyakude district, KwaZulu-Natal province, South Africa.

Methods: Snail sampling was done on 16 sites once every month by two people for 30 min at each site using the scooping and handpicking methods. Snails collected from each site were screened for schistosome mammalian cercariae by the shedding method. The negative binomial generalised linear mixed model $(\mathrm{glmm})$ was used to determine the relationship between abundances of the intermediate host snails and climatic factors [rainfall, land surface temperatures (LST), seasons, habitats, sampling sites and water physico-chemical parameters including $\mathrm{pH}$ and dissolved oxygen (DO)].

Results: In total, 1846 schistosomiasis intermediate host snails were collected during the study period. Biompharia pfeifferi was more abundant $(53.36 \%, n=985)$ compared to B. globosus $(46.64 \%, n=861)$. Bulinus globosus was recorded at 12 sites (75\%) and Bio. pfeifferi was present at 7 sites (43.8\%). Biompharia pfeifferi cohabited with B. globosus at all the sites it was present. High numbers of Bio. pfeifferi $(n=872,88.5 \%)$ and B. globosus $(n=705,81.9 \%)$ were found between winter and mid-spring. Monthly rainfall showed a statistically significant negative relationship with the abundance of $B$. globosus ( $p<0.05$ ). Dissolved oxygen $(D O)$ had a statistically significant positive relationship with the abundance of Bio. pfeifferi ( $p<0.05)$ while (LST) had a statistically significant negative relationship $(p<0.05)$. More B. globosus ( $8.9 \%, n=861)$ were shedding schistosome mammalian cercariae compared to Bio. pfeifferi $(0.1 \%, n=985)$ confirming the already documented high prevalence of S. haematobium in Ingwavuma compared to S. mansoni.
\end{abstract}

\footnotetext{
*Correspondence: manyangadze.tawanda@gmail.com

1 School of Nursing and Public Health, Department of Public Health Medicine, University of KwaZulu-Natal, Durban, South Africa

Full list of author information is available at the end of the article
}

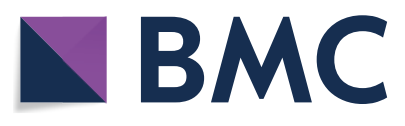

(c) The Author(s) 2021. This article is licensed under a Creative Commons Attribution 4.0 International License, which permits use, sharing, adaptation, distribution and reproduction in any medium or format, as long as you give appropriate credit to the original author(s) and the source, provide a link to the Creative Commons licence, and indicate if changes were made. The images or other third party material in this article are included in the article's Creative Commons licence, unless indicated otherwise in a credit line to the material. If material is not included in the article's Creative Commons licence and your intended use is not permitted by statutory regulation or exceeds the permitted use, you will need to obtain permission directly from the copyright holder. To view a copy of this licence, visit http://creativeco mmons.org/licenses/by/4.0/. The Creative Commons Public Domain Dedication waiver (http://creativecommons.org/publicdomain/ zero/1.0/) applies to the data made available in this article, unless otherwise stated in a credit line to the data. 
Conclusion: Results of this study provide updated information on the distribution of schistosomiasis intermediate host snails in the study area and contributes towards the understanding of the transmission dynamics of schistosomiasis at the micro-geographical scale in this area.

Keywords: Bulinus globosus, Biomphalaria pfeifferi, Schistosoma haematobium, Schistosoma mansoni, Malacology, Ecology

\section{Background}

Schistosoma haematobium and Schistosoma mansoni are endemic in sub-Saharan Africa [1,2] where they are mainly transmitted by Bulinus globosus and Biomphalaria pfeifferi, respectively $[3,4]$. The transmission and focal distribution of schistosomiasis are spatially and temporally restricted to water bodies inhabited by its obligate intermediate host snails [1] and human water contact [5]. Schistosomiasis is a serious public health problem in South Africa. An estimated 2-3 million children are infected, and 20 million (nearly $40 \%$ of the population) are at risk [6]. Previous studies conducted in Ingwavuma of uMkhanyakude district of South Africa showed that the prevalence of S. haematobium was around $37.5 \%$ [7].

The density and abundance of the intermediate host snails for schistosomiasis are influenced by environmental and climatic factors. Environmental factors include physical and chemical water properties such as temperature, turbidity, salinity, conductivity, $\mathrm{pH}$ and velocity and biological factors such as the availability of food, competition, predator-prey interactions, presence and density of aquatic plants [1, 5, 8-10]. Rainfall and temperature have been reported as the main climatic factors that determine the distribution of intermediate host snails [4, $11,12]$.

Although the afore-mentioned factors have been well studied, their importance varies from one ecological zone to another and even from one water body to another in the same ecological zone. The ecological factors influence the presence and abundance of intermediate host snails [13]. Thus, it is important to conduct studies at a local scale to identify factors that are significant in particular habitats to understand the schistosomiasis transmission dynamics [14]. Information on the ecology, temporal distribution and population dynamics of B. globosus and Bio. pfeifferi at a local scale is needed to enhance the knowledge of the spatial and seasonal distribution and factors influencing these patterns [11]. This provides critical data for the development and optimization of control and management of the disease [15]. Although much work has been done to unravel the limiting factors for snail habitat preferences $[11,12,16]$, it is important to gather data at a micro-geographical scale to understand the local transmission dynamics $[11,16,17]$.
The aim of this study was to describe and analyse the spatial and seasonal variation of B. globosus and Bio. pfeifferi in relation to a set of ecological factors at a micro-geographical scale in Ingwavuma of uMkhanyakude district, KwaZulu-Natal province, South Africa. Sound knowledge of the abundance and distribution of intermediate host snails is key to understanding schistosomiasis transmission in order to design effective intervention strategies in endemic areas [9].

\section{Methods \\ Study area}

The study was conducted in Ingwavuma (Fig. 1) of uMkhanyakude Health District in KwaZulu-Natal (KZN) province, South Africa, between May 2014 and May 2015. uMkhanyakude district is located in the northernmost eastern part of KwaZulu-Natal province of South Africa bordering Mozambique and Swaziland to the north and northwest respectively. The climate ranges from tropical to subtropical [18] with a hot wet summer and a cold dry winter. uMkhanyakude experiences low annual rainfall averaging $690 \mathrm{~mm}$ per year. More than half of the households in this area do not have access to piped clean water and have poor sanitary facilities $[19,20]$ making them vulnerable to water-borne diseases (WBDs) including schistosomiasis. The study area is approximately $40 \times 30 \mathrm{~km}$ and mostly characterised by seasonal streams flowing towards the Pongola flood plain and two main rivers (Pongolo and Ngwavuma) and there are two major dams-Nsunduza and Namaneni (Fig. 1).

\section{Surveys for schistosomiasis vector snails}

Bulinus globosus and Bio. pfeifferi snails were sampled from 16 sites distributed across the whole study area (Fig. 1) every month from May 2014 to May 2015. Sampling sites (including streams and dams) were identified based on observations on human water contact [21] and following Appleton and Miranda's [6] advice that snails need to be collected from suspected transmission sites and screened for infection for the purposes of local schistosomiasis surveillance. Twelve of the sites were located at pools along the seasonal streams and 4 sites were located at dams to capture the spatial variation in snail population dynamics at human water contact patterns and different habitats. The snail sampling 


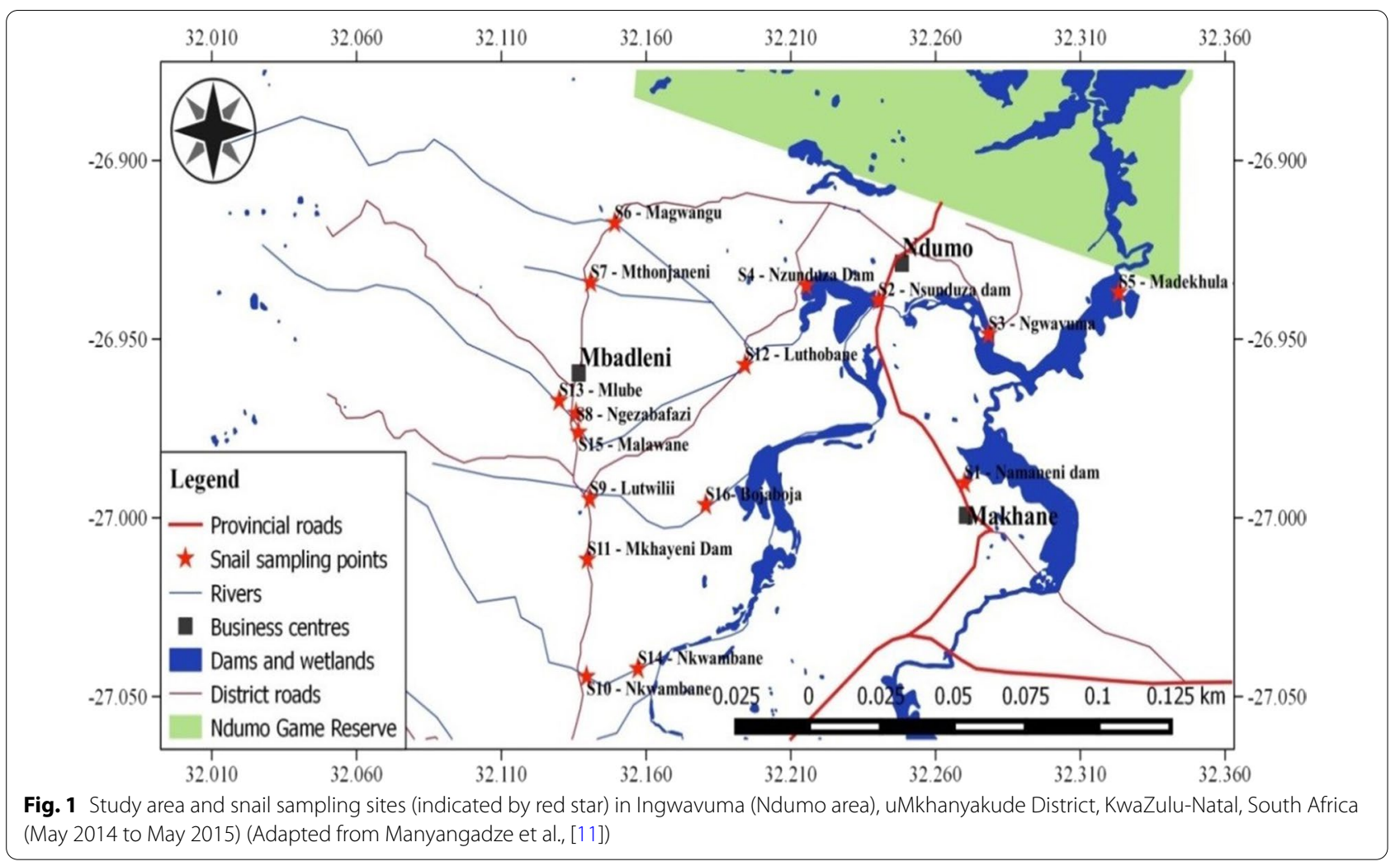

was semi-quantitative and was conducted by the same two technicians using scoops made from a kitchen sieve mounted on a broom stick [22, 23] and handpicking live visible snails for $30 \mathrm{~min}$ on each site [6]. Snails collected were morphologically identified [6] and expressed as number of snails.

\section{Cercarial shedding from host snails}

Snails collected from the study sites were identified as described by Brown [4] and screened for schistosome infection by the shedding method [24]. Briefly, snails were placed in small glass tubes containing $10 \mathrm{ml}$ of filtered pond water as described by Chimbari et al. [25] and exposed to strong artificial light to induce cercarial shedding [24]. Emerging cercariae were inspected under a dissecting microscope at $300 \times$ magnification $[6,21]$ and identified as described by Frandsen and Christensen [26]. Bulinus globosus and Bio. pfeifferi were designated as infected with mammalian schistosome cercarie if they shed bifurcated cercariae. The number of infected snails for each species at each site per month was recorded and expressed as a percentage [27].

\section{Environmental and climatic factors}

The environmental and climatic data were obtained through field measurement and remote sensing. Water temperature, $\mathrm{pH}$, salinity and conductivity were measured using a portable water meter (Hanna Instruments, Møllevænget, Sweden). Remote sensing data including the climatic data including rainfall from Climate Hazards InfraRed Precipitation (CHIRPS), minimum and maximum land surface temperature (LST)-Moderate Resolution Imaging Spectroradiometer (MODIS) were downloaded through the International Research Institute for Climate and Society (IRI) data library (http:// iridl.ldeo.columbia.edu/SOURCES/). The data on water physico-chemical parameters were gathered simultaneously with snail surveys. Climatic data were aggregated to monthly totals (rainfall) and monthly averages (temperature). These data were used to determine the relationship between the climatic factors and snail distribution by month, site, season and habitat. The year was divided into four seasons according to temperature and rainfall: rainy (December to February), post-rainy (March to May), cold-dry (June to August) and hot-dry (September to November) based on previous studies in the same area [11].

\section{Statistical analysis}

Negative binomial generalized linear mixed models (GLMMs) were used to model the abundance of B. globosus, Bio.pfeiferi and shedding B. globosus in relation 
to climatic factors, water physico-chemical properties, habitat types (i.e. dams and streams) and seasons with sites as random effects to ensure that intra-site correlation is accounted for in the parameter estimates. The models were fitted using the 'glmmTMB' [28] package in $\mathrm{R}$ Version 3.6.1. The collinearity and relationship between variables were checked using the variance inflation factor (VIF). Variables with VIF $>5$ indicate multicollinearity [29] and hence were not considered in the current analysis.

\section{Results}

\section{Spatial and seasonal variation of Bulinus globosus and Biomphalaria pfeifferi abundance}

In total, 1846 schistosomiasis intermediate host snails were collected during the study period (May 2014 to May 2015). Biompharia pfeifferi was more abundant (53.36\%, $n=985$ ) compared to B. globosus (46.64\%, $n=861)$. However, $B$. globosus was found at more sites $(12, n=16)$ compared to Bio. pfeifferi $(7, n=16)$. Bio. pfeifferi cohabited with B. globosus at all sites it was present. Most of the Bio. pfeifferi snails (99\%) were recovered from stream habitats while about $52.4 \%$ of $B$. globosus were recovered from stream habitats (Fig. 3c, d). High B. globosus counts were recorded from the end of the cold-dry season (August) to the mid hot-dry season (October 2014) and the counts decreased from November 2014 to May 2015 (Fig. 2a).

The climatic factors (rainfall, minimum temperature and maximum temperature) for Ingwavuma are shown in Fig. 2c. The variation in snail abundance by seasons is shown in Fig. 3a, b. High counts of Bio. pfeifferi were found during the cold-dry season (June to August 2014) with a sharp decrease from the beginning of the hot-dry season-September 2014 to May 2015 (Fig. 3a, b).

The summary of properties of the climatic and environmental exploratory variables for $B$. globosus from negative binomial regression in "glmmTMB" is shown in Table 1 . Monthly rainfall showed a statistically significant negative relationship with the abundance of $B$. globosus ( $p$-value $<0.05)$ while other variables did not show any statistically significant relationship (Table 1 ).

Only DO showed a statistically significant positive association with the abundance of Bio. pfeifferi $(p<0.05)$ (Table 1). Minimum LST had a statistically significant negative association with the abundance of Bio. pfeifferi $(p<0.01)$. Other variables did not show a statistically significant relationship with the abundance of Bio. pfeifferi (Table 1).

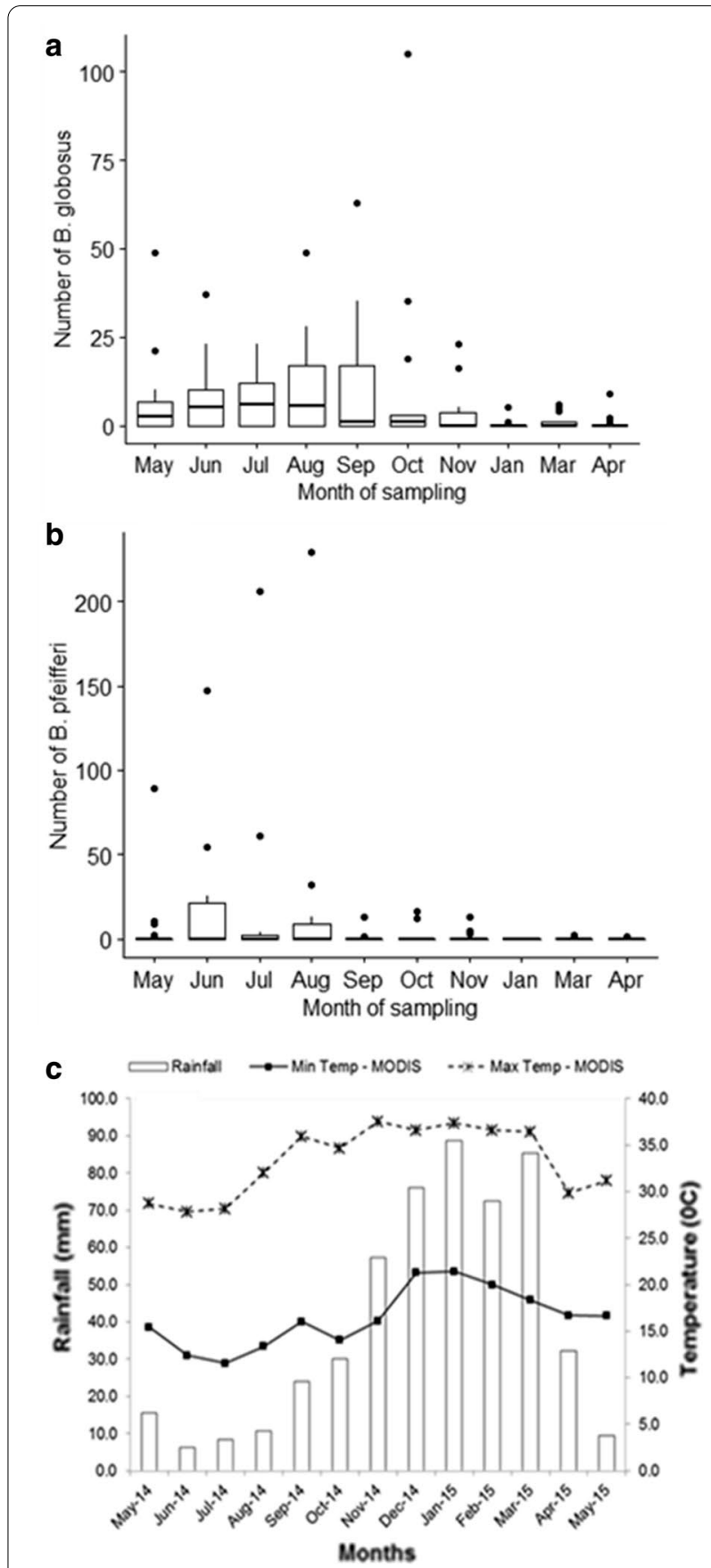

Fig. 2 Number of Bulinus globosus collected by month (a). Number of Biomphalaria pfeifferi collected by month (b) and monthly average rainfall and average minimum and maximum temperature in in Ingwavuma (Ndumo area) from May 2014 to May 2015 (c). Snails were collected by two men for 30 min once every month. For box and whisker plots in $\mathbf{a}$ and $\mathbf{b}$ the box represents the lower quartile (0.25), the median (0.5) and the upper quartile (0.75); the whiskers show the variability outside the box, i.e. the minimum excluding outliers and maximum also excluding outliers and outliers are shown as individual points 


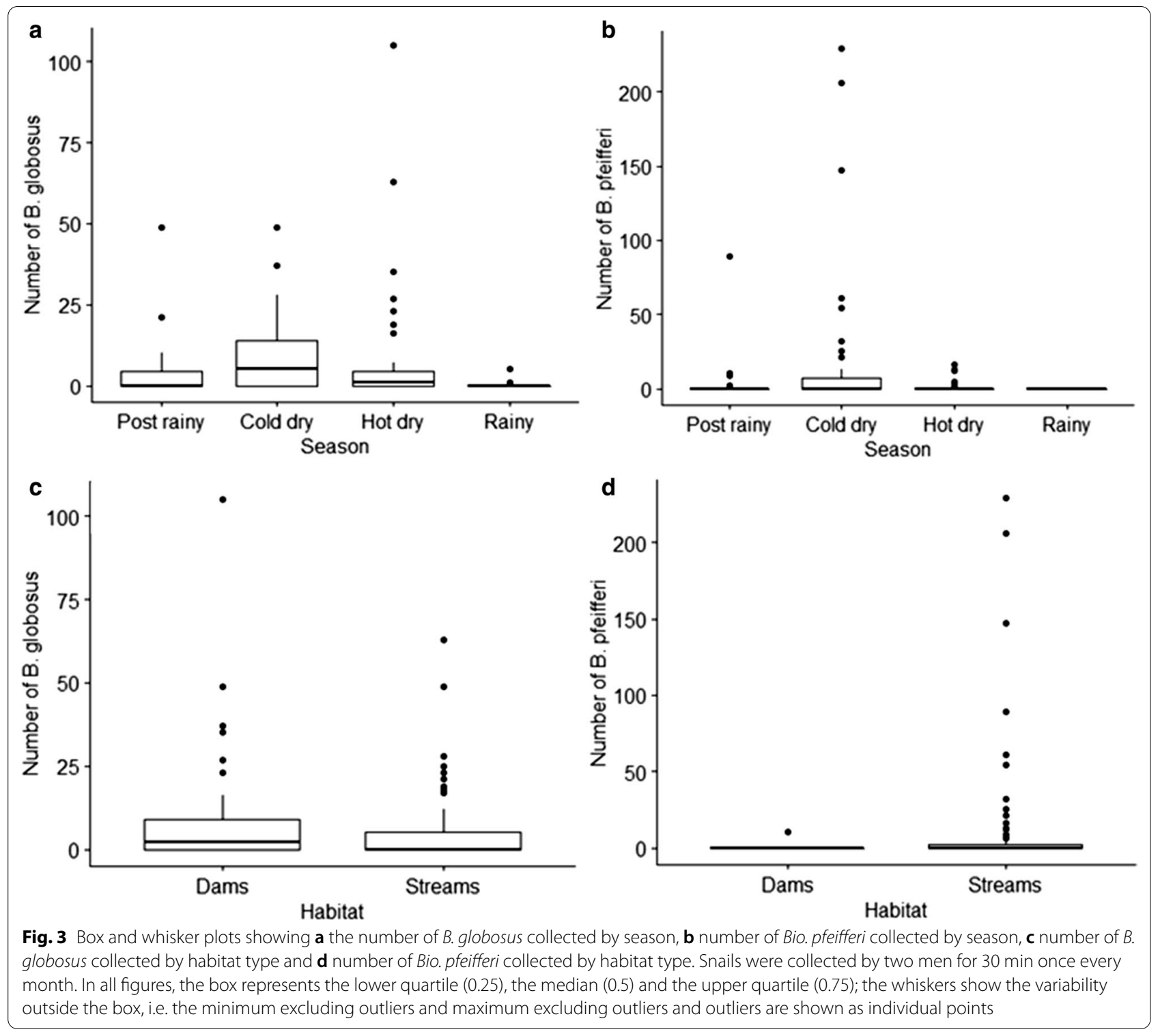

Spatial and seasonal variation of shedding Bulinus globosus and Biomphalaria pfeifferi abundance Bulinus globosus showed a continuous pattern of shedding mammalian schistosomes by seasons (Fig. 4) and Bio. pfeifferi only shed in August 2014 (0.22\%). Therefore, more B. globosus $(8.9 \%, n=861)$ were shedding mammalian cercaria compared to Bio. pfeifferi $(0.1 \%$, $n=985)$. More B. globosus snails were infected in the rainy season $(20 \%)$ as shown in Fig. 4. None of the variables considered in this study showed a statistically significant relationship with abundance of shedding $B$. globosus based on the negative binomial GLMM (Table 1). Although more shedding B. globosus were collected during the rainy season than in other seasons
(Fig. 4), the difference was not statistically significant (negative binomial GLMM; Table 1).

\section{Discussion}

Our findings on the presence of B. globosus and Bio. pfeifferi corroborate with those of N'Guessan et al. [30] and Mohammed [31]. We observed that snail abundance varied by sites and habitats indicating the focal nature of schistosomiasis. Monthly and seasonal variation was also observed. Snails tend to breed intensively and establish large populations following the onset of rains [32]. Populations of B. globosus in inland sites are rather erratic, mainly found during and a few months after the rainy season [33]. 
Table 1 Summary of properties of climatic and environmental exploratory variables for Bulinus globosus, Biomphalaria pfeifferi and shedding B. globosus from negative binomial regression GLMM in "glmmTMB package in R3.6.1"

\begin{tabular}{|c|c|c|c|c|c|c|}
\hline \multirow[t]{2}{*}{ Species } & \multirow[t]{2}{*}{ Fixed variables } & \multirow[t]{2}{*}{ Estimate } & \multirow[t]{2}{*}{ Confidence interval (CI) } & \multirow[t]{2}{*}{$p$-value } & \multicolumn{2}{|c|}{ Random effects ${ }^{a}$} \\
\hline & & & & & Variance & $\begin{array}{l}\text { Standard } \\
\text { deviation }\end{array}$ \\
\hline \multirow{10}{*}{$\begin{array}{l}\text { Bulinus } \\
\text { globosus }\end{array}$} & Intercept & 2.727 & -1.976 to 7.430 & 0.256 & 2.069 & 1.438 \\
\hline & Rainfall & -0.023 & -0.043 to -0.003 & $0.022^{*}$ & & \\
\hline & Minimum LST & 0.206 & -0.470 to 0.058 & 0.126 & & \\
\hline & Maximum LST & 0.071 & -0.086 to 0.228 & 0.374 & & \\
\hline & Water pH & -0.1235 & -0.471 to 0.201 & 0.452 & & \\
\hline & Dissolved oxygen & 0.007 & -0.001 to 0.016 & 0.076 & & \\
\hline & Habitat-streams & -0.210 & -1.979 to 1.559 & 0.816 & & \\
\hline & Season—hot dry & 0.475 & -0.490 to 1.441 & 0.335 & & \\
\hline & Season_post rainy & 0.155 & -1.077 to 1.387 & 0.806 & & \\
\hline & Season-rainy & 0.871 & -1.800 to 3.541 & 0.523 & & \\
\hline \multirow{10}{*}{$\begin{array}{l}\text { Biomphalaria } \\
\text { pfeifferi }\end{array}$} & Intercept & 6.126 & -2.980 to 15.233 & 0.187 & 10.22 & 3.197 \\
\hline & Rainfall & 0.012 & -0.016 to 0.039 & 0.410 & & \\
\hline & Minimum LST & -0.535 & -0.933 to -0.138 & $0.008^{*}$ & & \\
\hline & Maximum LST & -0.023 & -0.202 to 0.157 & 0.804 & & \\
\hline & Water pH & -0.506 & -1.097 to 0.087 & 0.094 & & \\
\hline & Dissolved oxygen & 0.015 & 0.003 to 0.026 & $0.012^{*}$ & & \\
\hline & Habitat—streams & 4.214 & -0.323 to 8.751 & 0.069 & & \\
\hline & Season—hot dry & -0.923 & -2.581 to 0.736 & 0.275 & & \\
\hline & Season_-post rainy & -0.205 & -1.726 to 1.317 & 0.792 & & \\
\hline & Season-rainy & -16.72 & -150.11 to 149.36 & 0.998 & & \\
\hline \multirow{10}{*}{$\begin{array}{l}\text { Shedding } \\
\text { Bulinus } \\
\text { globosus }\end{array}$} & Intercept & -5.361 & -13.219 to 2.498 & 0.181 & 3.229 & 1.797 \\
\hline & Rainfall & -0.022 & -0.066 to 0.022 & 0.321 & & \\
\hline & Minimum LST & -0.298 & -0.856 to 0.259 & 0.295 & & \\
\hline & Maximum LST & 0.134 & -0.167 to 0.436 & 0.384 & & \\
\hline & Water $\mathrm{pH}$ & 0.412 & -0.084 to 0.907 & 0.103 & & \\
\hline & Dissolved oxygen & 0.011 & -0.003 to 0.025 & 0.109 & & \\
\hline & Habitat—streams & -0.083 & -2.608 to 2.441 & 0.948 & & \\
\hline & Season—hot dry & -0.645 & -2.256 to 0.965 & 0.432 & & \\
\hline & Season_post rainy & -0.086 & -2.746 to 2.574 & 0.950 & & \\
\hline & Season-rainy & 1.624 & -3.413 to 6.661 & 0.527 & & \\
\hline
\end{tabular}

LST Land surface temperature

*Significant at $p<0.05$

a Sampling sites was the random effect. Reference category for seasons was cold dry season and for the habitats it was dams

Rainfall was negatively associated with both B. globosus and Bio. pfeifferi. However, that relationship was only stronger at a significant level for B. globosus. An association among snail distribution, abundance and rainfall has also been demonstrated in several studies. The condition of snail habitat is affected by rainfall in diverse ways. Snails cannot survive without water but too much water also reduces snail populations [34]. Rainfall contributes to the creation of temporary snail habitats and also supports creation of new habitats as there is transportation of snails by heavy rainfall. However, rainfall may also sharply reduce population densities [1] as the speed of the flowing water $>0.3 \mathrm{~m} / \mathrm{s}$ might be a limiting factor for snail abundance [35]. We did not measure the water velocity, an important parameter in elucidating the complex relationship between water velocity and vector snail density. During the post-rainy season and cold and dry seasons, the pools (along the streams) and dams provided suitable habitats for both B. globosus and Bio. pfeifferi as observed by Utzinger and Tanner [36] and [5]. However, in the hot dry season most of the rivers were dry; hence, few snails were found as they might have been aestivating as suggested by Betterton [37] and Rubaba 


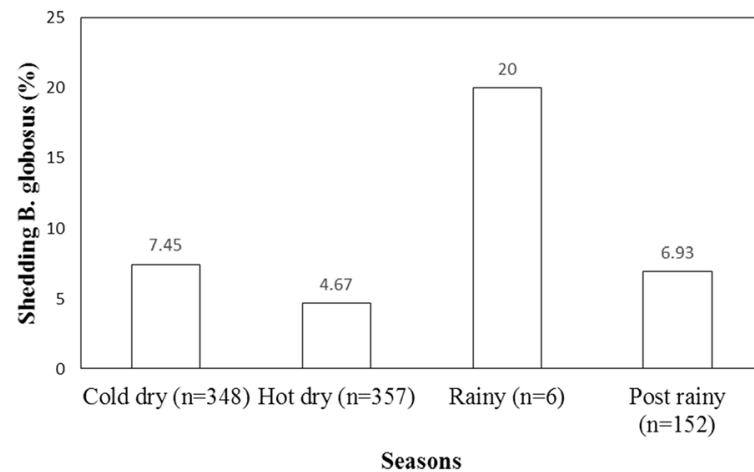

Fig. 4 Seasonal proportion (\%) of shedding Bulinus globosus in Ingwavuma (Ndumo area) area, uMkhanyakude, South Africa, from May 2014 to May 2015

et al. [38]. Thus, the shortage of surface water might be the main limiting factor for the abundance and density of snails in this particular area during the study period. Therefore, long dry periods that may be induced by climate change may result in fewer snails but there are also chances for the surviving snails to repopulate the habitats [38]. Further investigations during periods of normal rain might elucidate the relationship among rainfall, surface water levels and snail population densities and abundance. We have previously demonstrated that the availability of surface water (as represented by Normalised Difference Water Index) has a higher contribution in determining the spatial distribution of snail habitat in the same area based on the Maxent model [11]. However, according to Brooker [39], the spatial relationship between rainfall and snail population dynamics and infection transmission is difficult to measure since the effect of rainfall varies depending on the species of snail and the geographical location. Where snails occur in streams, as in the present study area, rainfall plays an important role in reducing snail populations and the population "starts afresh" after each rainy season, but the effect is only temporary as repopulation occurs rapidly [21].

The monthly Bio. pfeifferi abundance had a significant negative association with minimum land surface temperature. Temperature has also been identified as one of the key factors that influence the distribution of aquatic organisms, as it can be limiting for Bio. pfeifferi, when both high or low [40]. Snails have been observed to tolerate temperatures between 20 and $27{ }^{\circ} \mathrm{C}$ [41]. Temperatures lower than $20{ }^{\circ} \mathrm{C}$ tend to reduce breeding. Biomphalaria pfeifferi snails are less tolerant of higher temperatures and have not been observed where temperatures exceed $27{ }^{\circ} \mathrm{C}$ for more than $120 \mathrm{~h}$ per week but Bulinid snails seem to be better adapted to higher temperatures [14].

Biomphalaria pfeifferi showed high sensitivity to changes or differences in $\mathrm{pH}$ and $\mathrm{DO}$ compared to $B$. globosus. Kazibwe et al. [42] and Chimbari et al. [10] also noted the role played by these factors in the distribution of these snail species. Previous models have demonstrated that $\mathrm{pH}$ values and other physicochemical properties affect spatial distribution and snail densities [5, 43].

The percentage of infection in intermediate host snails could act as a composite index of both miracidial and cercarial densities [44] indicating the transmission of schistosomiasis in that particular area and time. Bulinus globosus snails had higher infection rates compared to Bio. pfeifferi, suggesting that S. haematobium is more prevalent than $S$. mansoni in Ingwavuma. Although we did not identify cercariae to the genus level, it has been observed that the species of snail from which schistosome cercariae are shed give a clue to their identity. Schistosoma haematobium cercariae are shed by B. globosus (and also B. africanus) and S. mansoni cercarie are shed by Bio. pfeifferi [6]. It was also noted that all the sites in this study were accessible to people and cattle. Appleton and Miranda [6] noted that it is helpful to keep notes on the usage of water bodies by both people and domestic animals as $S$. mattheei cercariae can also develop in B. globosus (and also B. africanus). Therefore, it is possible that there is $S$. mattheei from B. globosus. However, our results show that $S$. haematobium is prevalent as reported in previous prevalence survey studies $[7,45]$. This indicates that malacological surveys can complement the disease prevalence surveys in determining or planning of the control and management of schistosomiasis at micro-geographical scales. The results of this study contribute to knowledge on the dynamics of S. haematobium in Ingwavuma in support of Kabuyaya et al. [7], Manyangadze et al. [11], Saathoff et al. [45] and Manyangadze et al. [46]. Saathoff et al. [45] noted that in uMkhanyakude bilharzia is transmitted in summer to children engaged in recreational activities and our study has indicated that B. globosus snails were shedding cercarie in all seasons with the highest proportion in the rainy season (summer). However, we managed to collect samples in one month only in the rainy season (January 2015); hence, this may not be representative of the whole season. The presence of schistosome-infected B. globosus snails confirms that some of the sites considered in this study are S. haematobium transmission sites. The presence of uninfected B. globosus and Bio. pfeifferi snails at some sites indicates the sites' potential for transmission of both $S$. haematobium and S. mansoni. The infection rates from our study confirm the observation by Appleton and 
Miranda [6] who noted that snail infection rates are commonly between 2 and $10 \%$, but in some situations may be as high as $50 \%$. The same authors emphasised that finding even one infected snail in a water body is evidence of schistosomiasis transmission.

During the period of this study, there was no snail control or surveillance programmes in Ingwavuma. Therefore, the results of this study provide useful information on snail distribution and abundance for managing schistosomiasis at the micro-scale. As also noted by Olkeba et al. [47], the information regarding the spatial and temporal distribution of schistosomiasis intermediate host snails can be used for development and implementation of effective snail control programmes to complement other schistosomiasis control initiatives such as mass drug administration.

\section{Conclusion}

This study showed that B. globosus had a wider distribution compared to Bio. pfeifferi. B. globosus was found at more sites compared to Bio. pfeifferi but co-habitation of the two species was evident. Bulinus globosus numbers significantly inversely correlated with rainfall. Minimum land surface temperature was a significant limiting factor for Bio. pfeifferi abundance while DO had a significant positive correlation with Bio. pfeifferi. Bulinus globosus snails had higher infection rates compared to Bio. pfeifferi, indicating that S. haematobium is more prevalent than $S$. mansoni in Ingwavuma. This study provides updated information on distribution of schistosomiasis intermediate host snails in the study area and contributes towards the understanding of transmission dynamics of schistosomiasis at the microgeographical scale in this area.

\begin{abstract}
Abbreviations
CHIRPS: Climate Hazards Group InfraRed Precipitation with Station data; IRI: International Research Institute for Climate and Society; MODIS: Moderate resolution imaging spectroradiometer; LST: Land surface temperature; DO: Dissolved oxygen; Cl: Confidence interval; GLMM: Generalized linear mixed models; AIC: Akaike's information criterion.
\end{abstract}

\section{Acknowledgements}

The authors would like to express their appreciation to Malaria and Bilharzia in Southern Africa (MABISA) team members mainly in South Africa for field assistance. The research has been supported by the College of Health Sciences scholarship program at the University of KwaZulu-Natal and Malaria and Bilharzia in Southern Africa (MABISA) project funded by the WHO Special Programme for Research and Training in Tropical Diseases (TDR) and the Canadian International Development Research Centre (IDRC).

\section{Authors' contributions}

TM, MJC, SM conceptualised the study. TM, WS, OR collected the data. MJC, SM, WS, OR contributed on snail ecology. TM worked on online data access, analysed the data and drafted the manuscript. All authors read and approved the final manuscript.

\section{Funding}

The research has been supported by the College of Health Sciences scholarship program at the University of KwaZulu-Natal and Malaria and Bilharzia in Southern Africa (MABISA) project funded by the WHO Special Programme for Research and Training in Tropical Diseases (TDR) and the Canadian International Development Research Centre (IDRC).

\section{Availability of data and materials}

The data supporting the conclusions of this article are included within the article.

\section{Declarations}

Ethics approval and consent to participate

Not applicable.

\section{Consent for publication}

Not applicable.

\section{Competing interests}

The authors declare that they have no competing interests.

\section{Author details}

${ }^{1}$ School of Nursing and Public Health, Department of Public Health Medicine, University of KwaZulu-Natal, Durban, South Africa. ${ }^{2}$ Geography Department, Faculty of Science and Engineering, Bindura University of Science Education, Bag 1020, Bindura, Zimbabwe. ${ }^{3}$ Ministry of Health and Child Care, De Beers Research Laboratory, P. O. Box 197, Chiredzi, Zimbabwe. ${ }^{4}$ School of Life Sciences, University of KwaZulu-Natal, Durban, South Africa. ${ }^{5}$ Center for Zoonoses and Tropical Veterinary Medicine, Ross University School of Veterinary Medicine, Basseterre, St Kitts and Nevis.

Received: 23 October 2020 Accepted: 6 April 2021

Published online: 23 April 2021

\section{References}

1. Ofulla AV, Adoka SO, Anyona DN, Abuom PO, Karanja D, Vulule JM, et al. Spatial distribution and habitat characterization of schistosomiasis host snails in lake and land habitats of western Kenya. Res Manag. 2013;18:197-215.

2. World Health Organisation. WHO schistosomiasis fact sheet. Geneva: Switzerland; 2020.

3. Colley DG, Bustinduy AL, Secor WE, King CH. Human schistosomiasis. Lancet. 2014;383:2253-64.

4. Brown D. Freshwater snails of Africa and their medical importance. London:Taylor and Francis; 1994.

5. Moser W, Greter H, Schindler C, Allan F, Ngandolo B, Moto D, et al. The spatial and seasonal distribution of Bulinus truncatus, Bulinus forskalii and Biomphalaria pfeifferi, the intermediate host snails of schistosomiasis, in N'Djamena. Chad Geospat Health. 2014;9:109-18.

6. Appleton C, Miranda N. Locating bilharzia transmission sites in South Africa: guidelines for public health personnel. South African J Infect Dis. 2015;30(3):95-102.

7. Kabuyaya M, Chimbari MJ, Manyangadze T, Mukaratirwa S. Schistosomiasis risk factors based on the infection status among school-going children in the Ndumo area, uMkhanyakude district, South Africa. South African J Infect Dis. 2017;1 (1):1-6. https://doi.org/10.1080/23120053.2016. 1266139.

8. Gouvras AN, Allan F, Kinung S, Rabone M, Emery A, Angelo T, et al. Longitudinal survey on the distribution of Biomphalaria sudanica and B. choanomophala in Mwanza region, on the shores of Lake Victoria, Tanzania: implications for schistosomiasis transmission and control. Parasit Vectors. 2017;10(316):1-14.

9. Rabone M, Wiethase JH, Allan F, Gouvras AN, Pennance T, Hamidou AA, et al. Freshwater snails of biomedical importance in the Niger River Valley: evidence of temporal and spatial patterns in abundance, distribution and infection with Schistosoma spp. Parasit Vectors. 2019. https://doi.org/10. 1186/s13071-019-3745-8. 
10. Chimbari M, Kalinda C, Siziba N. Changing patterns of Schistosoma host snail population densities in Maun. African J Aquat Sci: Botswana; 2020.

11. Manyangadze T, Chimbari MJ, Gebreslasie M, Ceccato P, Mukaratirwa S, Moser W, et al. Modelling the spatial and seasonal distribution of suitable habitats of schistosomiasis intermediate host snails using Maxent in Ndumo area, KwaZulu-Natal Province, South Africa. Parasit Vectors. 2016:9(1):572. https://doi.org/10.1186/s13071-016-1834-5.

12. Stensgaard AS, Utzinger J, Vounatsou P, Hürlimann E, Schur N, Saarnak CFL, et al. Large-scale determinants of intestinal schistosomiasis and intermediate host snail distribution across Africa: does climate matter? Acta Trop. 2013;128(2):378-90. https://doi.org/10.1016/j.actatropica.2011. 11.010

13. Utzinger J, Mayombana C, Smith T, Tanner M. Spatial microhabitat selection by Biomphalaria pfeifferi in a small perennial river in Tanzania. Hydrobiologia. 1997;356:53-60.

14. Hussein MA, Obuid-Allah AH, Mahmoud AA, Fangary HM. Population dynamics of freshwater snails (Mollusca: Gastropoda) at Qena Governorate, upper Egypt. Egypt Acad J Biol Sci. 2011;3:11-22.

15. Kloos H, De Souza C, Gazzinelli A, Soares Filho BS, Da Costa TP, Bethony J, et al. The distribution of Biomphalaria spp. in different habitats in relation to physical, biological, water contact and cognitive factors in a rural area in Minas Gerais. Brazil Mem Inst Oswaldo Cruz. 2001;96(SUPPL.):57-66.

16. Pedersen UB, Midzi N, Mduluza T, Soko W, Stensgaard AS, Vennervald BJ, et al. Modelling spatial distribution of snails transmitting parasitic worms with importance to human and animal health and analysis of distributional changes in relation to climate. Geospat Health. 2014;8(2):335-43.

17. Adema CM, Bayne CJ, Bridger JM, Knight M, Loker ES, Yoshino TP, et al. Will all scientists working on snails and the diseases they transmit please stand up? PLoS Negl Trop Dis. 2012;6(12):e1835.

18. Schulze B. Climate of South Africa: general survey by BR Schulze. South Africa: Government Printer; 1965.

19. Pschorn-Strauss E. Bt cotton in South Africa: the case of the Makhathini farmers. Seedling. 2005.

20. Mulopo C, Kalinda C, Chimbari MJ. Contextual and psychosocial factors influencing the use of safe water sources: a case of Madeya village, Umkhanyakude district, South Africa. Int J Environ Res Public Health. 2020;17(4):1349.

21. Kariuki H, Clennon J, Brady M, Kitron U, Sturrock R, Ouma J, et al. Distribution patterns and cercarial shedding of Bulinus nasutus and other snails in the Msambweni area, Coast Province, Kenya. Am J Trop Med Hyg. 2004;70:449-56

22. Shiff $C$, Clarke $V$. The effect of snail surveillance in natural waterways on the transmission of Schistosoma haematobium in Rhodesia. Cent Afr J Med. 1967;13:133-7.

23. Coulibaly G, Madsen $\mathrm{H}$. Seasonal density fluctuations of intermediate hosts of schistosomes in two streams in Bamako. Mali J African Zool. 1990;104:201-12.

24. Kuntz R. Effect of light and tempetrature on emergence of schistosoma mansoni cercarie. Trans Am Microsc Soc. 1947;66(1):37-49.

25. Chimbari M, Chandiwana S, Ndlela B, Ndhlovu P, Chitsiko R, Thomson A, et al. Schistosomiasis control measures for small irrigation schemes in Zimbabwe. Final report on monitoring at Mushandike Irrigation Scheme. 1993.

26. Frandsen F, Christensen N. An introductory guide to the identification of cercariae from African freshwater snails with special reference to cercariae of trematode species of medical and veterinary importance. Acta Trop. 1984;41:p181.

27. Pfukenyi DM, Mukaratirwa S, Willingham AL, Monrad J. Epidemiological studies of Schistosoma mattheei infections in cattle in the highveld and lowveld communal grazing areas of Zimbabwe. Onderstepoort J Vet Res. 2006;73(3):179-91.

28. Brooks M, Kristensen K, van Benthem K, Magnusson A, Berg C, Nielsen A, et al. glmmTMB balances speed and flexibility among packages for zeroinflated generalized linear mixed modeling. R J. 2017:9:378-400.

29. Rogerson PA. Statistical methods for geography. London: Sage; 2001.

30. N'Guessan GC, Silué KD, Ba O, Ba H, Tian-Bi NT, Yapi GY, et al. Prevalence and seasonal transmission of Schistosoma haematobium infection among school-aged children in Kaedi town, southern Mauritania. Parasit Vectors. 2017;10(1):353.

31. Mohammed MHMA. Distribution, Ecological Factors and Trematode Infectivity of Snails in Mosana Lake, Kassala State. Sudan: University of Gezira; 2017.

32. Appleton C. Review of literature on abiotic factors influencing the distribution and life cycles of bilharziasis intermediate host snails. Malacol Rev. 1978;1:1-25.

33. Madsen $H$, Bloch $P$, Makaula $P$, Phiri H, Furu P, Stauffer JR. Schistosomiasis in Lake Malawîi Villages. EcoHealth. 2011;8(2):163-76.

34. Simoonga C, Utzinger J, Brooker S, Vounatsou P, Appleton CC, Stensgaard AS, Olsen A, Kristensen TK. Remote sensing, geographical information system and spatial analysis for schistosomiasis epidemiology and ecology in Africa. Parasitology. 2009;136(13):1683-93.

35. Utzinger J, Mayombana C, Mez K, Tanner M. Evaluation of chemical and physical-morphological factors as potential determinants of Biomphalaria pfeifferi. Mem Inst Oswaldo Cruz. 1997;92(3):323-8.

36. Utzinger J, Tanner M. Microhabitat Preferences of Biomphalaria pfeifferi and Lymnaea natalensis in a Natural and a Man-made Habitat in Southeastern Tanzania. Mem Inst Oswaldo Cruz. 2000;95(3):287-94.

37. Betterton C, Ndifon G, Tan R. Schistosomiasis in Kano State, Nigeria. II. Field studies on aestivation in Bulinus rohlfsi (Clessin) and B. globosus (Morelet) and their susceptibility to local strains of Schistosoma haematobium (Bilharz). Ann Trop Med Parasitol. 1988;82:571-9.

38. Rubaba O, Chimbari MJ, Mukaratirwa S. The role of snail aestivation in transmission of schistosomiasis in changing climatic conditions. African J Aquat Sci. 2016;41(2):143-50.

39. Brooker S. Spatial epidemiology of human schistosomiasis in Africa: risk models, transmission dynamics and control. Trans R Soc Trop Med Hyg. 2007; 101(1):1-8.

40. Appleton C, Eriksson IM. The influence of fluctuating above-optimal temperature regimes on the fecundity of Biomphalaria pfeifferi (Mollusca: Planorbidae). Trans R Soc Trop Med Hyg. 1984;78:49-54.

41. de Kock K, Van Eeden JA. Life table studies on freshwater snails: the effect of constant temperature on the population dynamics of Biomphalaria pfeifferi (Krauss). Potchefstroom University for CHE Publications; 1981.

42. Kazibwe F, Makanga B, Rubaire-Akiiki C, Ouma J, Kariuki C, Kabatereine $\mathrm{NB}$, et al. Ecology of Biomphalaria (Gastropoda: Planorbidae) in Lake Albert, Western Uganda: snail distributions, infection with schistosomes and temporal associations with environmental dynamics. Hydrobiologia. 2006;568(1):433-44

43. Adekiya TA, Aruleba RT, Oyinloye BE, Okosun KO, Kappo AP. The effect of climate change and the snail-schistosome cycle in transmission and biocontrol of schistosomiasis in sub-saharan Africa. Int J Environ Res Public Health. 2020;17(1):181.

44. Gryseels B, Polman K, Clerinx J, Kestens L. Human schistosomiasis. Lancet. 2006;368:1106-18.

45. Saathoff E, Olsen A, Magnussen P, Becker W, Appleton CC. Patterns of Schistosoma haematobium infection, impact of praziquantel treatment and re-infection after treatment in a cohort of schoolchildren from rural KwaZulu-Natal/South Africa. BMC Infect Dis. 2004;4:1-10.

46. Manyangadze T, Chimbari MJ, Gebreslasie M, Mukaratirwa S. Risk factors and micro-geographical heterogeneity of Schistosoma haematobium in Ndumo area, uMkhanyakude district, KwaZulu-Natal. South Africa Acta Trop. 2016;159:176-84.

47. Olkeba BK, Boets P, Mereta ST, Yeshigeta M, Akessa GM, Ambelu A, et al. Environmental and biotic factors affecting freshwater snail intermediate hosts in the ethiopian rift valley region. Parasites Vectors. 2020;13(292):113. https://doi.org/10.1186/s13071-020-04163-6.

\section{Publisher's Note}

Springer Nature remains neutral with regard to jurisdictional claims in published maps and institutional affiliations. 